\title{
Abstracts
}

This section of the JouRNAL is published in collaboration with two abstracting fournals, ABSTRACTS OF WORLD MEDICINE and OPHTHALMIC LITERATURE, published by the British Medical Association. The abstracts are divided into the following sections:

Syphilis (Clinical, Therapy, Serology, Biological False

Positive Phenomenon, Pathology, Experimental). Gonorrhoea.

Nongonococcal Urethritis and Allied Conditions.
Reiter's Disease and Allied Conditions. Antibiotics and Chemotherapy.

Public Health and Social Aspects. Miscellaneous.

After each subsection of abstracts follows a list of articles that have been noted but not abstracted.

\section{Syphilis, Clinical}

Nephrotic Syndrome associated with Secondary Syphilis. An Immune Deposit Disease BRAUNSTEIN, G. D., LEWIS, E. J., GALVANEK, E. G., HAMILTON, A., and BELL, W. R. (1970) Amer. F. Med., 48, 643

Described here is a patient in whom the nephrotic syndrome developed during the course of secondary syphilis. A renal biopsy was performed, and the specimen showed perivascular mononuclear cell infiltration, interstitial oedema, and glomerular mesangial cell proliferation under light microscopy. Subepithelial hump-like electron dense deposits with epithelial cell foot process fusion in the glomeruli were found on electron microscopy. Immunofluorescent microscopy demonstrated a granular deposition of gamma G2 lambda globulin in the glomerulus but was unable to detect complement deposition in the same location. Although the antigen involved in the glomerular deposit was not identified, the findings suggest that acute syphilitic nephrosis is an immune deposit disease. Authors' summary

Charcot Joints storey, G. O. (1970) Rheum. phys. Med., 10, 312 figs, 44 refs

\section{Liver Disease associated with Early Syphilis BARER, A. L., KAPLAN, M. M., WOLFE, H. J., and MCGoWAN, J. A. (1971) New Engl. f. Med., 284, 14221 fig., 6 refs}

Liver Disease associated with Secondary Syphilis LEE, R. V., THORNTON, G. F., and CONN, H. O.

(1971) New Engl. J. Med., 284, 14231 fig., 8 refs

\section{Atrophic Luetic Glossitis CAPTLINE, A. M., WHITE, N. S., MERKOW, L. P., and SNYDER, S. P. (1970) Oral Surg., 30, 1924 figs, 5 refs}

Congenital Syphilis: Resurgence of an Old Problem WILKINSON, R. H., and HELLER, R. M. (1971) Pediatrics, 47, 275 figs, 10 refs

\section{Syphilis, Therapy}

\section{Diagnosis and Treatment of} Syphilis [Review Article] SPARIING, P. F. New Engl. F. Med., 284, 642 Bibl.

\section{Syphilis, Serology}

Sensitivity and Specificity of Automated Serologic Tests for Syphilis CATE, T. R., TIEMANN, G. G., and PRINCE, J. (1971) Amer. F. clin. Path., 55, 735

In a study carried out at Duke University, North Carolina, U.S.A., 4,212 sera from routine tests on admissions to hospital over a 2-month period were tested by the VDRL slide, automated reagin (AR), and automated Kolmer tests. 227 sera were reactive in one or more of these procedures; these, with the immediately preceding non-reactive sera, were examined by the manually performed Kolmer and FTA-ABS tests. On the basis of the results of the FTA-ABS test, which was reactive in 139 and non-reactive in 315, the performance of the other procedures is given as:

$\begin{array}{ccc}\text { Test } & \begin{array}{c}\text { Sensitivity } \\ (\%)\end{array} & \begin{array}{c}\text { Specificity } \\ (\%)\end{array} \\ \text { VDRL } & 73 & 96 \\ \begin{array}{c}\text { Automated } \\ \text { reagin }\end{array} & 71 & 97 \\ \begin{array}{c}\text { Manual } \\ \text { Kolmer }\end{array} & 66 & 73 \\ \begin{array}{c}\text { Automated } \\ \text { Kolmer }\end{array} & 60 & 67\end{array}$

A review of the case records showed that the FTA-ABS reactive sera came from patients with late or latent infections. The poor specificity of the Kolmer tests was (partly) influenced by the method of selection of sera, as: 104 of the original 4,212 were selected because of reactivity in the automated Kolmer test alone; only eleven of these proved to be reactive in the FTA-ABS test.

Comparison of titres in the VDRL and AR-reactive sera showed a high correlation; the AR titres tended to be one dilution higher than those of the VDRL. Integration of the AR test with other routinely performed automated tests would make it economically competitive as a routine serological screening test for syphilis.

A. E. Wilkinson

\section{A Lyophilization Medium for FTA-ABS Test Antigen}

HUNTER, E. F., CREIGHTON, E. T., and LEWIS, J. S. (1971) Hlth Lab. Sci., 8,35

It has been found difficult to lyophilize suspensions of Treponema pallidum so that, when reconstituted, they are suitable for use as antigen in the absorbed fluorescent treponemal antibody test. The authors, working at the Center for Disease Control, Atlanta, Ga., U.S.A., have previously described a suspending medium which overcomes this (Hlth Lab. Sci. (1970), 
7, 237). This paper gives the experimental background to its development.

Treponemes were extracted from the testes of infected rabbits and washed in phosphate buffered saline (pH 7.2) containing 0.6 per cent. sodium azide. Suspension of the washed treponemes in 1 per cent. bovine albumin minimized loss of organisms during lyophilization and helped to stabilize pH. The addition of dextrose was found to improve the morphology of the treponemes as seen by darkground illumination with visible light. Cystic degenerative changes in the reconstituted suspensions on storage at 5 to $10^{\circ} \mathrm{C}$. could be prevented by the incorporation of magnesium salts in the suspending fluid. The $\mathrm{pH}$ tended to rise during lyophilization and this appeared to be associated with the use of sodium azide. The medium finally chosen was $0.1 \mathrm{M}$ phosphate buffered saline ( $\mathrm{pH}$ 6.8) containing 1 per cent. bovine albumin, $0.0375 \mathrm{M}$ dextrose, and 0.01 $\mathrm{M} \mathrm{MgCl}{ }_{2}$. When washed treponemes are lyophilized in this medium, they show good morphology on reconstitution, stain well in the FTA-ABS test, and preserve their reactivity in fixed slides stored at a low temperature. A. E. Wilkinson

[Reprinted from Abstracts on Hygiene, by permission of the Editor.]

\section{Evaluation of a Qualitative Haemagglutination Test for Antibodies to Treponema pallidum LE CLAIR, R. A. (1971)} F. infect. Dis., 123, 668

Treponemal haemagglutination (TPHA) tests were performed at the University of California Center for Health Sciences on 340 sera from patients whose clinical status was known. These comprised 100 sera from apparently healthy persons with negative TPI and VDRL (tube) tests; 100 from patients classed as biological false positive reactors on the basis of negative TPI tests; 130 from patients with syphilis at various stages; eight from patients with yaws; and two from patients with pinta. The test was performed with reagents from a commercial source and the technique is fully described.

In the nonsyphilitic group there were three positive tests among the healthy persons and five among the false positive reactors. The TPHA test was positive in 120 of the 130 syphilitic sera; negative results were found in five of ten sera from patients with primary syphilis, three of fifty with latent syphilis, and two of ten with congenital infections. All the yaws sera were positive, but those from the two patients with pinta gave negative results. 100 randomly selected sera were re-tested, the reproducibility was 98 per cent.

The test was easy to perform and the author thinks that it may be an acceptable alternative to the confirmatory tests at present in use. [A specificity of 96 per cent. in the nonsyphilitic group of sera is low for a confirmatory test.]

\section{A. E. Wilkinson}

[Reprinted from Abstracts on Hygiene, by permission of the Editor.]

\section{Evaluation of the Automated Fluorescent Treponemal Antibody Test for Syphilis} HORNSTEIN, J. H., GATES, C. W., and BRANDON, S. M. (1971) F. Lab. clin. Med., 77, 885

In tests carried out at the Georgia Department of Public Health, Atlanta, Ga., U.S.A., sera were tested in parallel by the manually performed FTA-ABS test and an automated procedure. Sera were received as fresh or frozen specimens and were divided into multiple aliquots; the frozen specimens were stored at $-20^{\circ} \mathrm{C}$. and the fresh specimens kept at $4^{\circ} \mathrm{C}$. and tested within a week. All samples were coded and examined by the same technologist in batches of up to thirty a day by the manual (M) method and up to fifty a day by the automated (A) technique.

Complete agreement between the two methods was found with 93.4 per cent. of 741 specimens and partial agreement with 2.3 per cent. Agreement was slightly closer with fresh than with frozen specimens. 463 specimens were from patients classed as not having syphilis; of these, the $M$ method gave 0.9 per cent. and the A method 0.4 per cent. reactive results; borderline reactions were found with 0.2 per cent. and 1.1 per cent. respectively. The specificity of the two methods was thus about equal. The $M$ method was found to be more sensitive; it gave 99.6 per cent. reactive and 0.4 per cent. borderline results compared with 89.5 per cent. and 2.6 per cent. by the $A$ method in tests on 229 specimens from patients with syphilis. This greater sensitivity was most marked in specimens from patients with late latent infections; in 110 of these, the $M$ method was reactive in 99.1 per cent. but the A method in only 81.8 per cent. A. E. Wilkinson

[Reprinted from Abstracts on Hygiene, by permission of the Editor.]

\section{Significance of Cardiolipin}

Immunofluorescence WRIGHT,

D. J. M., and DONIACH, D. (1971)

Proc. roy. Soc. Med., 64, 4193 figs, 28 refs

Role of Sorbent in the Absorbed Fluorescent Treponemal Antibody (FTA-ABS) Test WILKINSON, A. E., and WISEMAN, C. C. (1971) Proc. roy. Soc. Med., 44, 4222 figs, 14 refs

Automated Reagin Test for Syphilis in a Multichannel Blood Grouping Machine SCHROETER, A. L., TASWELL, H. F., KIERLAND, R. R., and SWEATT, M. A. (1971) Amer. F. clin. Path., 56, 43 2 figs, 6 refs

\section{Syphilis, BFP phenomenon}

Use of Standard Serological Tests for Syphilis in Screening for Autoimmune Connective Tissue Disease. Chronic Biological False Positive Reactions and Anticomplementary Activity Johansson, E. A. (1970) Acta derm.venereol. (Stockh.), 50, 305

6,737 consecutive inpatients admitted to the Department of Dermatology of the University Central Hospital, Helsinki, Finland, were studied. VDRL, Kahn, Kolmer, and Reiter protein complement-fixation tests were performed as screening tests for syphilis. 31 patients ( 0.5 per cent.) had chronic biological false positive (BFP) reactions as judged by the absence of clinical or historical evidence of syphilis and negative TPI and FTAABS tests. 25 sera were anticomplementary (AC) in one or both of the complement-fixation tests on one 
specimen only, but in 24 patients the AC reaction was found repeatedly. Four sera showed both BFP and persistent AC reactions.

Both BFP and AC reactions were found more frequently in females than in males. Thirteen of the BFP reactors were assessed as having definite or probable systemic lupus erythematosus (SLE) and one discoid LE. Three had rheumatoid arthritis, three sarcoidosis, one purpura, and one malignant lymphoma and myelosis; the other nine had miscellaneous dermatoses. Most of these sera showed other abnormalities, such as the presence of antinuclear factor, cryoglobulins, rheumatoid factor, or hypergammaglobulinaemia.

Persistent AC reactions were found in the sera of six patients with SLE, three with necrotizing vasculitis, three with purpura, three with malignant lymphoma and myelosis, and nine with miscellaneous dermatoses. The other abnormal antibodies mentioned above were frequently detected; hypergammaglobulinaemia was present in fifteen of the AC sera.

The significance of the chronic BFP reaction as a pointer to the presence of autoimmune connective tissue disease is well established; persistent AC reactions may also give a useful clue to the presence of an underlying disease process. A. E. Wilkinson

\section{Biological False Positive VDRL Test in Malaria HAGHIGHI, L., DOUST, J. Y., and BOROOMAND, $\mathrm{K}$.} (1970) Trop. geogr. Med., 22, 482 In a survey carried out at the Pahlavi University, Shiraz, Iran, VDRL slide tests were performed on all patients suspected of having malaria, as well as the examination of Giemsa-stained blood films. These were positive for malaria in 162 instances; 158 were infections with $P$. vivax and four with $P$. falciparum. The VDRL test was weakly reactive with fifteen sera and reactive with five; three of these last five patients had a history of syphilis. The incidence of presumed false positive reactions was $10 \cdot 7$ per cent., but no specific treponemal tests were performed to confirm the diagnosis. Reactivity was commonest in the second and third weeks after the initial attack and was not apparently related to the density of parasitaemia at the time of diagnosis. No BFP reactions were seen in the four patients infected with $P$. falciparum.

A. E. Wilkinson

\section{Syphilis, Pathology}

\section{Uveitis and Intraocular}

Treponemes WHITFIELD, R., and wirostKo, E. (1970) Arch. Ophthal. (Chicago), 84, 121 fig., 9 refs

Of fifty patients with active uveitis, six had organisms indistinguishable from $T$. pallidum in the aqueous humour and fifteen had serological test results suggestive of syphilis. A control series of fifty specimens of aqueous humour from cataract patients showed no aqueous or serological abnormality. All six patients with aqueous treponemes denied having had syphilis, whereas ten of 44 patients with negative results had had the disease. The authors admit that the results are difficult to evaluate and fall back on altered host/organism relationships to explain them

\section{F. H. Kelsey}

\section{Cell-mediated Immunity and} Lymphocyte Transformation in Syphilis LEVENE, G. M., WRIGHT, D. J. M., and TURK, J. L. (1971)

Proc. roy. Soc. Med., 64, 426

3 figs, 18 refs

\section{Syphilis, Experimental}

\section{Study of a Strain of Yaws}

Treponeme isolated on the Ivory

Coast (Étude d'une souche de

tréponème isolée de pian en Côte

d'Ivoire) MALGRAS, J., BASSET, A., MALEVILLE, J., BERGOEND, H.,

BASSET, M., and ERNOLIEFF, S. (1970)

Bull. Soc. Path. exot., 63, 652

The clinical manifestations of yaws as it is seen on the Ivory Coast are reviewed. The behaviour of a strain of treponemes (Y) isolated from a child with early yaws is compared with that of strains isolated from endemic syphilis (ES) in Senegal and from venereal syphilis in Strasbourg (VS), and with the rabbit-adapted Nichols strain of Treponema pallidum.

The strains were maintained by passage in rabbits by the testicular route. With successive passages, the time elapsing between inoculation and the development of clinical orchitis lessened and eventually stabilized at 10 days for the ES and Nichols strains, about 17 days for the VS, and 20 days for the $Y$ strain. It was noted that the $\mathrm{Y}$ strain produced a transient 'pre-orchitis' 4 to 5 days after inoculation. No treponemes could be found on aspiration of the testis at this stage, but typical clinical orchitis developed on about the 20th day and later subsided. It was not followed by the formation of a syphilomatous ulcer involving the scrotal skin and underlying testis although this occurred in about a fifth of the rabbits infected with the Nichols and ES strains. These last two strains produced indurated lesions containing treponemes when inoculated into the scarified skin of the back; this did not occur with the $Y$ strain. In the early passages of the $Y$ and ES strains, the TPI test remained negative for long periods, but after the seventh passage it became positive after 45 to 60 days.

[Some of these differences between strains may have been due to progressive increase in the number of treponemes inoculated at successive passages as the strains became adapted to the new host species.]

A. E. Wilkinson

[Reprinted from Abstracts on Hygiene, by permission of the Editor.]

Resistance and Serological Changes in Rabbits immunized with Virulent Treponema pallidum Sonicate IZZAT, N. N., KNOX, J. M., DACRES, W. G., and SMITH, E. B. (1971) Acta derm.venereol. (Stockh.), 51, 157

The immunizing agent in these experiments carried out at the Baylor College of Medicine, Houston, Texas, U.S.A., was a suspension of virulent Nichols strain Treponema pallidum containing $5 \times 10^{7}$ organisms in $4 \mathrm{ml}$. These were disrupted ultrasonically and $1 \mathrm{ml}$. Escherichia coli lipopolysaccharide was added as an adjuvant. Groups of three rabbits were injected weekly for 16 weeks:

(a) With $0.5 \mathrm{ml}$. intramuscularly;

(b) With $0.5 \mathrm{ml}$. into the foot pad;

(c) With $0.3 \mathrm{ml}$. intravenously.

VDRL, FTA-ABS, and TPI tests were performed at the 8 th and 16 th weeks and then monthly for $3 \mathrm{mths}$ after challenge with $5 \times 10^{4} T$. palli- 
dum intradermally at four sites on the back.

Three animals died during the experiment, one in group $a$ and two in group $c$. All the survivors developed reactive VDRL and FTA-ABS tests during immunization, but the TPI test remained negative in all. None showed any evidence of immunity on challenge, darkground-positive lesions developing within 15 to 20 days in the test animals and in three control rabbits which had not been immunized. A. E. Wilkinson

[Reprinted from Abstracts on Hygiene, by permission of the Editor.]

\section{Gonorrhoea}

\section{Gonorrheal Conjunctivitis}

THATCHER, R. W., and PETTIT, T. H. (1971) F. Amer. med. Ass., 215, 14946 figs, 8 refs

The authors report four cases of gonococcal conjunctivitis diagnosed at the Jules Stein Eye Institute, Los Angeles, in the 6-month period from July, 1969, to January, 1970. Two occurred in new-born babies who had received eye drops of silver nitrate at birth and two in adults. The authors comment that as gonorrhoea increases in the United States of America there is a danger that gonococcal conjunctivitis and its sequelae will increase in similar proportions. Because of the increasing resistance of the gonococcus to penicillin the patients were treated with penicillin by injection and with broad spectrum antibiotics either topically or systemically.

[The use of eye drops containing a high concentration of penicillin (such as $1 \mathrm{~m} . \mathrm{u} . / \mathrm{ml}$.) has advantages (Ridley (1958), Trans. ophthal. Soc. U.K., 78, 335 , and the use of probenecid in addition to systemic penicillin will render that therapy more effective.]

\section{Eric Dunlop}

\section{Single Oral Dose Ampicillin-} Probenecid Treatment of Gonorrhoea in the Male

KVALE, P. A., KEYS, T. F., JOHNSON, D. W., and HOLMES, K. K. (1971) $\mathcal{F}$. Amer. med. Ass., 215, 14491 fig., 17 refs

The finding that many cases of uncomplicated acute gonococcal urethritis in males no longer respond to doses of penicillin which were ade- quate only a few years ago has been attributed to various causes, including errors in diagnosis, but the authors of this paper from the U.S. Naval Preventive Medicine Unit No. 6, Pearl Harbour, Hawaii, have no doubt that the main reason is that the organism has developed a relative resistance to penicillin. Single large doses of penicillin are, in their view, preferable to repeated smaller doses. The authors base this opinion on the results of a study of naval personnel in the Philippines between July, 1967, and October, 1968. They excluded from the series all patients with a history of hypersensitivity to penicillin and all who could not be followed up for 21 days after treatment. All the patients were men and the diagnosis was confirmed by Gram-stained smears from urethral secretion. Cultures (Thayer-Martin) were used only in the event of failure of treatment. Six methods of treatment were used:

(1) 68 patients received $3.5 \mathrm{~g}$. ampicillin by mouth in one dose;

(2) 373 patients received 1 g. probenecid by mouth, followed $1 \mathrm{hr}$ later by $3.5 \mathrm{~g}$. ampicillin in a single dose, and then further doses (each of $0.5 \mathrm{~g}$.) of probenecid 6,12 , and $18 \mathrm{hr}$ after the ampicillin dose;

(3) 110 patients received the same treatment as those in Group 2 but in addition $0.5 \mathrm{~g}$. ampicillin was given by mouth four times daily for 7 days;

(4) 27 patients received the same routine of treatment as in Group 2 , but with a dose of $3.5 \mathrm{~g}$. phenoxymethyl penicillin instead of ampicillin;

(5) 21 patients received the same treatment as those in Group 4, with the substitution of a single dose of $5 \mathrm{~g}$. instead of $3.5 \mathrm{~g}$. phenoxymethyl penicillin;

(6) 21 patients received the same treatment as those in Group 5, except that each received a single dose of $7.5 \mathrm{~g}$. phenoxymethyl penicillin instead of $5 \mathrm{~g}$.

The results were as follows:

Group 1, 41 patients were followed up with twelve (29.3 per cent.) failures:

Group 2, 202 with eight (4.0 per cent.) failures;

Group 3, 100 with no failures;
Group 4, 27 with fourteen (52 per cent.) failures;

Group 5, seventeen with eleven (65.0 per cent.) failures;

Group 6, twenty with five (25.0 per cent.) failures.

All patients were re-examined 7 and 21 days after the completion of treatment. None of these methods appeared to affect the incidence of postgonococcal urethritis, which varied from 34.8 to 62 per cent. in the six groups.

The authors conclude that, in this series, the combination of ampicillin and probenecid as in Groups 2 and 3 gave an acceptable cure rate in the treatment of acute gonorrhoea in males. Ampicillin alone was much less effective and the combination of phenoxymethyl penicillin and probenecid was not significantly better than standard treatment with parenteral penicillin.

The authors point out that their study was carried out in an area in which the incidence of strains of gonococci known to be relatively resistant to penicillin is exceptionallyce high. [They appear to take little? account of the possible significance of post-gonococcal urethritis, making the comment that this condition was not always clinically significant because over half the patients with this condition were asymptomatic and required no further treatment.]

\section{A. f. King}

\section{Treatment of Uncomplicated} Gonorrhoea with a Single Oral Dose of Doxycycline [In English] LIDÉN, S., HAMMAR, H., HILLSTRÖM, L., WALLIN, J., and ÖHMAN, S. (1971) Acta derm.-venereol. (Stockh.), 51, 22114 refs

The authors of this paper from University Hospital, Uppsala, Sweden, see the ideal alternative to penicillin as an antibiotic free from immunological cross-reaction with penicillin, effective in a single dose for both sexes, and effective when given orally. Doxycycline, an antibiotic of the tetracycline group, has these characteristics. It is also rapidly absorbed from the gastrointestinal tract and gives high and prolonged concentrations in serum and tissues. They here report a trial of doxycycline in the treatment of gonorrhoea. 
250 patients (150 men and 100 women) with uncomplicated gonorrhoea were selected to exclude travellers and the pregnant. The criterion of diagnosis was positive culture. For both sexes routine treatment was with $300 \mathrm{mg}$. doxycycline in a single oral dose. Except for the first 25 patients, all received 'juice and biscuits' before treatment. This minimized the incidence of nausea, which occurred in 35, and of vomiting, which occurred in 9 . Vomiting did not impair therapeutic results, which indicated the speed of absorption of the antibiotic.

The criterion of failure or reinfection was also a positive culture. Among the 247 patients returning for at least two follow-up examinations there were six (2.4 per cent.) failures and three ( 1.2 per cent.) re-infections. These results compare with 2.0 per cent failures and 2.4 per cent. probable re-infections after $2 \cdot 2$ m.u. penicillin used in another series. [In neither series was the antibiotic sensitivity of the local gonococci determined.]

The authors conclude that doxycycline is highly effective in cases of uncomplicated gonorrhoea and is a suitable alternative for the penicillinsensitive.

Gastrointestinal side-effects were frequent in spite of precautions, but owing to the rapidity of absorption they seldom affected the results in terms of success or failure of cure.

$$
\text { R. S. Morton }
$$

\section{Sensitivity to Antibiotics of $\boldsymbol{N}$. gonorrhoeae isolated in 1966 and 1968 from Patients in North Sweden BERGMAN, $s$., and TÄRNVIK, A. (1970) Acta derm.-venereol. (Stockh.), 50, 317} The sensitivity of gonococci isolated at the University of Umeå, Sweden, to four antibiotics is reviewed. A plate dilution method was used to determine sensitivity to penicillin, the results being expressed as the 50 per cent. inhibitory concentration $\left(\mathrm{IC}_{50}\right)$. Disc tests were used against streptomycin, tetracycline, and chloramphenicol, but the concentrations are not stated.

311 strains were tested in 1966 and 335 in 1968.4 .8 and 11.0 per cent. of strains which were insensitive to penicillin $\left(\mathrm{IC}_{50}>0.1 \mathrm{u} . / \mathrm{ml}\right.$.) were found during these two periods; the least sensitive (4 strains) had an $\mathrm{IC}_{50}$ of 1.5 to $3.0 \mathrm{u} . / \mathrm{ml}$. In 1966 the mean $\mathrm{IC}_{50}$ of all strains was $0.02 \mathrm{u} . / \mathrm{ml}$; in 1968 this had risen to $0.03 \mathrm{u} . / \mathrm{ml}$. This difference, which is statistically significant, was also found when the insensitive strains were excluded from consideration, suggesting that a progressive shift towards decreased sensitivity was occurring.

2.25 per cent. of the strains isolated in 1966 were resistant to streptomycin; in 1968 this percentage had risen to 6 per cent. All but one of these streptomycin-resistant strains showed insensitivity to penicillin. No decrease in sensitivity to tetracycline or to chloramphenicol was observed during the study.

A. E. Wilkinson

\section{Demonstration of Neisseria gonorrhoeae in Prostatic Fluid after Treatment of \\ Uncomplicated Gonorrhoeal}

Urethritis DANIELSSON, D., and

Molin, L. (1971) Acta derm.-venereol. (Stockh.), 51, 73

Alternate males attending the Department of Dermatology, Karolinska Hospital, Stockholm, with uncomplicated gonorrhoea during a period of 3 months were studied. The diagnosis was established by the examination of stained smears and cultures and the patients were treated with a single injection of 1 m.u. aqueous benzyl penicillin plus 1.5 m.u. aqueous procaine penicillin. All the isolates were sensitive to penicillin with a minimum inhibitory concentration of less than $0.1 \mathrm{u} . / \mathrm{ml}$.

The patients were followed up by three examinations at weekly intervals, which included the examination of smears and cultures of any urethral secretions. 2 to 3 weeks after treatment the prostatic fluid was examined by Gram-stained smears and by direct fluorescent antibody (FA) staining. Gram-negative organisms resembling gonococci were seen in 21 of 33 specimens; the FA stain was positive in eleven of these and in two additional cases. Cultures on all 33 specimens were negative. No further treatment was given, but 22 of the patients with previous positive findings were re-examined after 2 to 3 weeks. The FA tests were then all negative, but sparse Gram-negative diplococci were still seen in smears from ten patients, nine of whom had had previous positive FA tests; cultures were again uniformly negative. Gonococcal complement-fixation tests were performed on sera from twenty patients; ten were positive at titres of 1 in 5 to 1 in 80 , and seven of these sera came from patients from whom positive FA tests had been obtained.

Prostatic fluids were examined from a control group of 25 males who had no previous history of urethritis but were attending the clinic for a variety of skin conditions. Smears, cultures, and FA tests were all negative.

The possible epidemiological significance of these findings is discussed. A. E. Wilkinson

A Rational Basis for the Treatment of Gonorrhoea MORTON, R. S., and ONN, L. Y. (1971) Singapore med. F., 12, 864 refs

Gonorrhoea in Women HART, $M$. (1971) F. Amer. med. Ass., 216, 16094 refs

Therapy of Female Gonorrhoea with Cephaloridine SHAPIRO, L. H., and LENTZ, J. W. (1970) Amer. F. Obstet. Gynec., 108, 471 10 refs

Trimethoprim for the Prevention of Overgrowth by Swarming Proteus in the Cultivation of Gonococci ÖDEGAARD, K. (1971) Acta path. microbiol. scand., 79B, 545 6 refs

Epidemiology of Gonococci with Decreased Sensitivity to Penicillin in Malmö, South

Sweden MÖLLER, H. (1971)

Acta derm.-venereol. (Stockh.), 51, 77 2 figs, 12 refs

\section{Nongonococcal urethritis and allied conditions}

Nifuratel compared with

Metronidazole in the Treatment of Trichomonal Vaginitis EVANS, B. A., and CATTERALL, R. D. (1970)

Brit. med. F., 2, 3358 refs

56 patients were treated with nifuratel and 59 with metronidazole at the Middlesex Hospital. Nifuratel was given by mouth in dosage of $200 \mathrm{mg}$. three times daily for 7 days concur- 
rently with one $250 \mathrm{mg}$. pessary nightly for 10 nights. Metronidazole was given by mouth only in dosage of $200 \mathrm{mg}$. three times daily for 7 days. In the nifuratel group 47 returned for further examination and eighteen (38 per cent.) were considered cured on the evidence of at least one set of tests (wet smears and cultures) after treatment. Thirteen were still positive at the first post-treatment examination and eleven at the second. Two others were detected by vaginal culture at the third and fourth examinations. Three patients had to stop treatment because of adverse effects; two had a rash and the third drowsiness and loss of memory. In the metronidazole group 49 attended for follow-up and 42 (85 per cent.) were considered cured. Three were positive at the first post-treatment examination and three at the second. Culture was positive in one other patient at the fourth examination. One patient had nausea and vomiting but continued to take the tablets. The results indicated that nifuratel was not a satisfactory substitute for metronidazole in the treatment of trichomoniasis. P Rodin

\section{Birth Weight and Genital Mycoplasmas in Pregnancy BRAUN, P., YHU-HSIUNG LEE, KLEIN, J. O., MARCY, S. M., KLEIN, T. A., CHARLES, D., LEVY, P., and KASS, E. H. (1971) New Engl. F. Med., 284, 167 18 refs}

Mycoplasmas are commonly present in the genital tracts of pregnant women, but their pathogenicity is poorly understood. Mycoplasma hominis has been cultured from the blood in occasional cases of febrile abortion and has been recorded from the tissues of both aborted and still-born infants. T-strains of mycoplasma (tiny colonies of mycoplasmas with special growth characteristics, not related to any particular mycoplasma subtype) have been isolated from fetal membranes after spontaneous abortion.

The present study from Harvard Medical School and other centres was undertaken to ascertain the effect of genital mycoplasma infection on the outcome of the pregnancy in an unselected series of 688 patients from the prenatal clinic at Boston City Hospital. All women who registered and were followed up at the clinic between February and July 1969 were studied; 46 per cent. were black, 32 per cent. were white, and 22 per cent. were of mixed racial origin. The population under investigation was mainly drawn from the lower socioeconomic groups.

Urine and cervical cultures were collected at the first clinic visit at 23.3 \pm 8 (SD) weeks after the last menstrual period and again at $34.5 \pm 3.3$ weeks and at term. Nose, throat, and vaginal cultures were obtained from newborn infants during the first 3 days of life.

Information was available on the outcome of the pregnancy for 571 of the 688 women initially entering into the study; from 485 of the 571 satisfactory cultures were obtained and the analysis of the results concerns only those patients. A total of 464 women were delivered of a single live child and 6 pregnancies produced twins; there were ten stillbirths (including one still-born twin) and six spontaneous abortions.

The 485 patients studied were divided into four groups; 78 where cultures at the first prenatal visit were negative, 22 where a positive culture for $M$. hominis was obtained, 177 where T-strains were found, and 207 where both $M$. hominis and T-strains were isolated. The mean gestational length of the four groups as a whole was 39.2 weeks and there were no significant differences in the length of gestation among the groups.

The mean birth weight of the 384 infants whose mothers had T-strains isolated was 3,099 \pm 595 (SD) $\mathrm{g}$. whereas that of the 100 babies from mothers without $T$-strains was 3,297 $\pm 510 \mathrm{~g}$. This difference was highly significant $(P<0.003)$. The birth weight of infants from mothers with T-strains was still significantly lower than those of mothers without $T$ strains when only live births were considered or if cases of twins and Caesarean section were excluded from the analysis.

Although the birth weight of the infants whose mothers had $M$. hominis cultured during pregnancy were less than of those whose mothers did not have the organism isolated, this difference was not significant at the 5 per cent. level. If twins and Caesarean sections were excluded from this analysis a significant difference was observed ( $P=0.034)$. This may be accounted for by the high degrec of association between $T$-strains and $M$. hominis in this group, for in the case of those with $M$. hominis alone no significant difference was seen.

Relations between the presence of mycoplasmas and risk factors for low birth weight were sought. There was no significant relation between the presence of either $\mathrm{T}$-strains or $M$. hominis and bacteriuria, cigarette smoking, previous premature births, or previous still-births or miscarriages. There was no relation to the development of toxaemia or antepartum haemorrhage.

Both T-strains and M. hominis were found more commonly in black patients than in the other racial groups, and the mean birth weight of the infants of black mothers was significantly less than that of the infants of white or mixed racial mothers $(3,087 \pm 561 \mathrm{~g}$. as against $3,204 \pm 578$ g.; $P=0.017$ ). Nonetheless, when the effect of mycoplasmas upon birth weight was analysed separately for black patients the strong association between $T$ strain infection and low birth weight was still seen. Mean birth weights were significantly less in the T-straininfected patients in the case of black mothers $(P=0.025)$ but not for white and mixed racial groups $(P=0.077)$.

$T$-strains were isolated from 28 per cent of babies weighing less than 2.5 $\mathrm{kg}$. at birth and 5 per cent. of babies of more than $2.5 \mathrm{~kg}$. This difference was significant $(P<0.001)$. The difference in isolation rates for $M$. hominis was not significant $(\mathrm{P}=$ 0.192).

The results demonstrate a relation between genital $\mathbf{T}$-strain mycoplasma infection in pregnancy and low birth weight. Whether this relationship represents a cause of low birth weight or merely marks those patients with a predisposition to produce infants of low birth weight cannot be deduced from this study. The authors suggest that a therapeutic trial aimed at eliminating mycoplasmas found during pregnancy may clarify this point. Cyril Chantler

Mycoplasmas and the Evidence for Their Pathogenicity in Man 
Taylor-Robinson, D. (1971) Proc. roy Soc. Med., 64, 3137 refs

\section{Incidence of Candida albicans in Women using Oral}

Contraceptives JENSEN, H. K., HANSEN, P. A., and BLOM, J. (1970) Acta obstet. gynaec. scand., 49, 293 2 figs, 20 refs

\section{Antibiotics and chemotherapy}

\section{Biological Availability of Oxytetracycline $\mathrm{HCl}$ Capsules. A Comparison of All Manufacturing Sources} Supplying the United States Market BLAIR, D. C., BARNES, R. W., WILDNER, E. L., and MURRAY, W. J. (1971) F. Amer. med. Ass., 215, 251 1 fig., 14 refs

Drugs having biological standards are said to be biologically equivalent when administration in equivalent dosage shows comparable biological availability, but they do not always have therapeutic equivalence. Furthermore, drugs which are chemically equivalent are not always biologically equivalent. A comparison of the biological equivalence of $250-\mathrm{mg}$. oxytetracycline $\mathrm{HCl}$ capsules from the eleven manufacturers supplying the U.S.A. market has been made by the Food and Drug Administration, Washington, DC. In a series of twelve two-way cross-over studies on 100 fasting normal male subjects aged 21 to 54 yrs, the serum tetracycline levels for each subject were measured by the cylinder-plate method 2, 3, and $6 \mathrm{hrs}$ after the oral administration of a $250-\mathrm{mg}$. capsule of oxytetracycline $\mathrm{HCl}$. Capsules supplied by the original manufacturer (Pfizer) were taken as the reference product. Of the 100 subjects, 76 had three tests, twelve had two tests, and twelve had one test.

The serum concentrations of products supplied by the other ten manufacturers varied considerably and in seven cases the mean values were about 50 per cent. lower $(P<0.005)$ than those for the reference product. The results confirm earlier observations that chemically equivalent oxytetracycline capsules, which satisfy existing official certification requirements, are not necessarily biologically equivalent.

F. E. Page

\section{Public health and social aspects}

\section{Frequency of Treponemal}

Infection among the Bedik of

Senegal (La fréquence des

tréponèmatoses chez les Bedik du

Sénégal) CIRERA, P., BOULOUX, C., and Gomila, J. (1970) Bull. Soc.

Path. exot., 63, 666

The Bedik are a farming and hunting community, some 1,500 in number, who live in Eastern Senegal, South of the Gambia, and who have not mixed with neighbouring tribes. During a survey of blood groups, specimens of blood were obtained from 797 persons (53 per cent.) and sent by air to Toulouse where Reiter protein complement-fixation (RPCF) and Kline microflocculation tests with a cardiolipin antigen were performed. The latter was definitely positive on 121 sera, but 139 weak $(+)$ and nineteen doubtful reactions were also found. The RPCFT was reactive with 180 sera, doubtful with four, and negative with 576. 37 sera were so strongly anticomplementary that no result could be obtained.

The authors comment on the unusually high proportion of weak positive Kline reactions; most of these sera gave negative RPCF tests, so that their specificity is suspect. Despite this, there appears to be a high incidence of treponemal infection among the Bedik. Whether this is due to yaws, to endemic syphilis, or to venereal syphilis is not known; no clinical manifestations of venereal syphilis were noted on a cursory examination of the patients.

[An analysis of the incidence of positive results in various age groups would have been informative.]

\section{A. E. Wilkinson}

[Reprinted from Abstracts on Hygiene, by permission of the Editor.]

\section{Syphilis and Gonorrhoea at the} Dermatological Clinic of the University of Munich, 1959-69 (Lues und Gonorrhoe an der Dermatologischen Universitätsklinik München, 1959-1969) PETZOLDT, D., NEUMANN, K., and SAUER, H. (1971) Hautarzt, 22, 2531 fig., 17 refs

Yaws in an Isolated Australian Aboriginal Population GARNER, M. F., BACKHOUSE, J. I., and
TIBBS, G. J. (1970) Bull. Wld Hlth Org., 43, 6033 refs

Coloured Immigrants and Venereal Diseases in Great Britain Hossain, A. S. M. T. (1970) Indian Practit., 23, 75345 refs

Socio-economic Status of Male Pakistani Immigrants attending Venereal Disease Clinics in England HOSSAIN, A. S. M. T. (1970) Pakistan med. Rev., 5, 47113 refs

Living Environment of Pakistani Immigrants attending Venereal Disease Clinics in Great Britain Hossain, A. S. M. T. (1971) Publ. Hlth (Lond.), 85, 12314 refs

Sexual Behaviour of Male Pakistanis attending Venereal Disease Clinics in Great Britain Hossain, A. S. M. T. (1971) Soc. Sci. and Med., 5, 227 1 fig., 29 refs

Increase in Venereal Disease Med. F. Aust. (1970), 2, 759

The V.D. Patient in General

Practice Wigfield, A. S. (1971)

Newc. med. F., 31, 200

\section{Miscellaneous}

Association of Genital

Herpesvirus with Cervical Atypia and Carcinoma in situ ROYSTON, I., and AURELIAN, L. (1970) Amer. $\mathcal{F}$. Epidemiol., 91, 5312 figs, 24 refs

[From the Departments of

Microbiology and Laboratory Animal Medicine, Johns Hopkins University

School of Medicine, Baltimore,

Maryland]

A neutralization test (multiplicity analysis), using an artificial mixture of two strains of herpes simplex virus, a prototype of the genital strain and a laboratory strain designated HSV$M P$, was used to differentiate antibodies to the genital and facial strains (Types 1 and 2) of herpes simplex virus in sera of patients with cervical neoplasia. The prevalence of antibody to the genital strain in women without cancer was found to increase both with increasing age and with decreasing socioeconomic class. The frequency of antibody among women with cervical neoplasia was uniformly high and thereby independent of age and socioeconomic class. Antibody 
was detected in 98 per cent. of 110 patients with cervical carcinoma at any stage of the disease, in 55 per cent. of the matched control women, and 50 per cent. of those women with malignancies at sites other than the cervix. Statistically significant differences $(P<.0005)$ were observed between antibodies to genital herpesvirus in patients with pre-invasive carcinoma (atypia 95 per cent., carcinoma in situ 100 per cent.) and a matched control population, differences which do not exist with regard to two other venereally transmitted diseases, trichomoniasis and syphilis. The data support the hypothesis that genital herpesvirus may be responsible for the induction of squamous neoplasia in the human cervix; however, further studies are required to determine whether the association is a causal one. Authors' summary

\section{Antibodies to Herpesvirus} hominis Types 1 and 2 in Humans. I. Patients with Genital Herpetic Infections NAHMIAS, A. J., JOSEY, W. E., NAIB, Z. M., LUCE, C. F., and DUFFEY, A. (1970) Amer. F. Epidemiol., 91, 5391 fig., 17 refs [From the Departments of Pediatrics, Preventive Medicine, Gynecology and Obstetrics, and Pathology, Emory University School of Medicine and Grady Memorial Hospital, Atlanta, Georgia]

Use of a microneutralization test and quantal method of analysis permits the differentiation of Herpesvirus hominis (HVH) antibodies into Type 1 , intermediate or Type 2 antibodies. A study of sera obtained from 239 individuals of varying ages in a lower socioeconomic population showed that, beyond the new-born age group, Type 2 or intermediate antibodies were found only in sera of individuals beyond the age of 14 years. In a second study of 122 patients with genital HVH Type 2 infections, onethird were found to be primary cases, one-fourth had Type 1 antibodies, another fourth had intermediate antibodies, and 16 per cent. had Type 2 antibodies in their acute serum. These results demonstrate that Type $2 \mathrm{HVH}$ infections can occur in individuals with prior Type 1 infections and provide further evidence that intermediate antibodies are dual antibodies, representing prior exposure to both HVH Type 1 and 2 infection.

$$
\text { Authors' summary }
$$

\section{Women with Cervical Cancer}

NAHMIAS, A. J., JOSEY, W. E., NAIB, Z. M., LUCE, C. F., and GUEST, B. A. (1970)

Amer. F. Epidemiol., 91, 54720 refs

The microneutralization test, permitting differentiation of Herpesvirus hominis ( $\mathrm{HVH})$ type antibodies, was used to study sera obtained from 167 women [mainly lower socioeconomic group] with invasive and pre-invasive anaplastic lesions of the cervix. Similar serologic studies were done on an equal number of women matched for socioeconomic status, race, and age. The percentage of women having Type 2 and dual antibodies in the study and control groups was found to be as follows:

(a) Invasive carcinoma 83 per cent.; controls 35 per cent.;

(b) In situ cervical carcinoma 70 per cent.; controls 24 per cent.;

(c) Histologically confirmed cervical dysplasia 56 per cent.; controls 18 per cent.;

(d) Cervical atypia diagnosed by cytological examination only 40 per cent.; controls 20 per cent.

There thus appeared to be a gradation in the percentages of women with Type 2 antibodies from cytologically diagnosed atypia to invasive cervical carcinoma. The findings presented here, as well as those reported elsewhere, demonstrate a definite association between genital herpes and cervical anaplasia. Further investigation is needed to substantiate a causal relationship Authors' summary

\section{Antibodies to Genital Herpes \\ Virus in Patients with \\ Carcinoma of the Cervix \\ RAWLS, W. E., GARDNER, H. L., and KAUfMAN, R. L. (1970) Amer. $\mathcal{F}$. \\ Obstet. Gynec., 107, 7102 figs, 21 refs}

The authors, from Houston, Texas, studied the distribution of antibodies to Type 2 herpes virus among a lower socioeconomic group, consisting mainly of members of 'minority races' and a higher socioeconomic group, mostly Caucasians. Antibody to the virus was quantitated by examining the kinetics of neutralization and by a microneutralization test comparing the antibody titres to Type 1 and Type 2 virus.

Among women in the lower socioeconomic group, Type 2 antibody was found in 72 of 87 women (83 per cent.) with invasive carcinoma, nine of 27 ( 33 per cent.) with carcinoma in situ, and eleven of 51 (22 per cent.) matched controls. In the higher socioeconomic group, nine of 29 (31 per cent.) women with carcinoma in situ had Type 2 antibody and four of 46 (9 per cent.) matched controls. Thus, while the occurrence of antibodies among the patients with carcinoma in situ was not significantly different from the control group in the lower socioeconomic class, a significant association with the lesion was demonstrated in the higher socioeconomic class. Whereas the occurrence of antibody increased with age among the control groups, this was not found in those with carcinoma in situ, suggesting that altered susceptibility to virus infection which might accompany neoplastic change@ did not occur. If it is true that proportion of invasive carcinomas develops in carcinoma in situ lesions the risk of developing invasive carcinoma would appear to be greater in women with carcinoma in situ and herpes virus Type 2 antibodies than in women without such antibodies.

P. Rodin

Genital Herpesvirus Infection AMSTEY, M. S., and BALDUZZI, P. C. (1970) Amer. F. Obstet. Gynec., 108, 1882 figs, 16 refs

Wart Viruses ALMEIDA, J. D., and ORIRL, J. D. (1970) Brit. F. Derm., 83, 6984 refs

\section{Erythroplasia of Queyrat}

LEWIS, R. J., and BENDL, B. J. (1971)

Canad. med. Ass. F., 104, 148

7 figs, 6 refs

Antibacterial Effect of a Chlorhexidine-Lidocaine Jelly upon the Flora of the Anterior Male Urethra TABACOV, I., and TSATSOVA, v. (1970) Int. Urol. Nephrol., 2, 1993 figs, 3 refs

Condyloma Acuminatum SWERDLOW, D. B., and SALVATI, E. P. (1971) Dis. Colon Rect., 14, 226 5 figs, 16 refs 